\title{
Mature Pancreatic Teratoma
}

National Cancer Institute

\section{Source}

National Cancer Institute. Mature Pancreatic Teratoma. NCI Thesaurus. Code C95559.

A mature teratoma that arises from the pancreas. 